\title{
Compound auroral micromorphology: ground-based high-speed imaging
}

\author{
Ryuho Kataoka ${ }^{1,2^{*}}$, Yoko Fukuda ${ }^{3}$, Yoshizumi Miyoshi ${ }^{4}$, Hiroko Miyahara ${ }^{5}$, Satoru Itoya ${ }^{6}$, Yusuke Ebihara ${ }^{7}$, \\ Donald Hampton ${ }^{8}$, Hanna Dahlgren ${ }^{9,10}$, Daniel Whiter ${ }^{11}$ and Nickolay Ivchenko ${ }^{9}$
}

\begin{abstract}
Auroral microphysics still remains partly unexplored. Cutting-edge ground-based optical observations using scientific complementary metal-oxide semiconductor (sCMOS) cameras recently enabled us to observe the fine-scale morphology of bright aurora at magnetic zenith for a variety of rapidly varying features for long uninterrupted periods. We report two interesting examples of combinations of fine-scale rapidly varying auroral features as observed by the sCMOS cameras installed at Poker Flat Research Range (PFRR), Alaska, in February 2014. The first example shows that flickering rays and pulsating modulation simultaneously appeared at the middle of a surge in the pre-midnight sector. The second example shows localized flickering aurora associated with growing eddies at the poleward edge of an arc in the midnight sector.
\end{abstract}

Keywords: Aurora; Magnetosphere-ionosphere coupling; Wave-particle interaction

\section{Findings}

Introduction

In the low-beta plasma condition of the magnetosphereionosphere (M-I) coupled region, Alfvén waves hold time varying electric field parallel to the ambient magnetic field (Hasegawa 1976; Goertz and Boswell 1979). This is a consequence of the electron inertia when the wavelength perpendicular to the ambient magnetic field is an order of electron skin depth. Since the spatial scale is typically approximately $1 \mathrm{~km}$ when mapped to the ionosphere, the inertial Alfvén waves (IAWs) are one of the most important theoretical bases to understand the diverse microstructures of rapidly varying aurora. Observations of fine-scale auroral morphology are therefore important to visualize the fundamental wave-particle interactions working in the M-I coupled region, which are also potentially useful to diagnose the local plasma environment.

Flickering aurora consists of small-scale columns ( 1 to $12 \mathrm{~km}$ width and 10 to $40 \mathrm{~km}$ height) with periodic intensity variations ( 3 to $15 \mathrm{~Hz}$ ) in discrete auroral arcs and is often observed associated with auroral breakup

\footnotetext{
* Correspondence: kataoka.ryuho@nipr.ac.jp

${ }^{1}$ National Institute of Polar Research, 10-3 Midori-cho, Tachikawa, Tokyo

190-8518, Japan

²Department of Polar Science, The Graduate University for Advanced Studies (SOKENDAI), 10-3 Midori-cho, Tachikawa, Tokyo 190-8518, Japan

Full list of author information is available at the end of the article
}

events (Kunitake and Oguti 1984). Temerin et al. (1986, 1993) suggested that electromagnetic ion cyclotron (EMIC) waves that occur below the inverted-V acceleration region can accelerate and modulate the field-aligned electrons over a broad energy range to produce flickering aurora. The EMIC wave model is similar to the IAW model except that it includes finite frequency effects. A possible source of the EMIC waves is an instability in the double layer or electrostatic shock that produces the electron beam. The appearance of flickering aurora can be modeled as the interference of IAW or EMIC waves (Sakanoi et al. 2005). Gustavsson et al. (2008) showed that a variety of structures of flickering aurora can be modeled by varying the parameters of multiple interfering EMIC waves. Whiter et al. (2008) showed that flickering aurora is linked temporally to auroral activity, but not spatially on small scales, which is consistent with the interfering EMIC waves. Whiter et al. (2010) showed that the parallel phase velocity of the EMIC waves is the primary factor in determining the energy of wave-accelerated electrons responsible for flickering aurora, which is consistent with the resonant acceleration and deceleration model of IAW/ EMIC waves in combination with inverted- $V$ acceleration as suggested by Chen et al. (2005). Yaegashi et al. (2011) and Kataoka et al. (2011b) showed several examples that the observed spatiotemporal scale of monochromatic flickering events is consistent with the O+ EMIC waves. Michell 
et al. (2012) showed that there is a lack of flickering spectral power at perpendicular wavenumber of larger than $2 \times 10^{-3} \mathrm{~m}^{-1}$, suggesting the existence of a minimum spatial scale for flickering auroral patches of approximately the $\mathrm{O}+$ ion gyro-radius (approximately $1 \mathrm{~km})$ at the interaction altitude. The expected altitude of modulation source (assuming the O+ EMIC waves) varies widely from 2,000 km to 7,000 km (e.g., Sakanoi et al. 2005; Whiter et al. 2010; Yaegashi et al. 2011).

It has been suggested for a long time that dynamic aurora structures are energetic. Hallinan (1976) suggested that 'spirals' of $>50 \mathrm{~km}$ imply upward current, and the threshold current density for distortion of an auroral arc was estimated as $2.5 \times 10^{-6} \mathrm{~A} \mathrm{~m}^{-2}$. Electrostatic shear-induced instability of a thin current sheet (Wagner et al. 1983) can explain the formation of auroral 'folds' (10 to $50 \mathrm{~km}$ ) and 'curls' (approximately $5 \mathrm{~km}$ ) (Hallinan and Davis 1970). The threshold current for the double-layer formation associated with curls and folds may also be assumed as the same order of magnitude as required for spirals. Ivchenko et al. (2005) showed that curls are caused by the precipitation of energetic electrons with a lack of low-energy precipitation, while in the 'rays' both high- and low-energy precipitation were present simultaneously, suggesting that curls are caused by the electrostatic instability of the precipitating electron sheet, while rays are likely to be a result of IAW. Chaston and Seki (2010) suggested that the formation of curls and folds may indicate the existence of a resistive layer which may be considered as the auroral acceleration region, while absence of resistive layer may be consistent with the recently found rapidly varying boundary features known as 'ruffs' (Dahlgren et al. 2010). The smallest-size distortions of auroral arcs are the 'filaments' of approximately $100 \mathrm{~m}$ width, and the rapidly varying very narrow auroral elements are associated with the precipitation of monoenergetic electrons (Lanchester et al. 1997). It is important to note that curls and filaments are more energetic or associated with higher electron fluxes than surrounding aurora structures (Lanchester et al. 2009). Dahlgren et al. (2008a) reported that some auroral filaments are caused by higher energy precipitation within regions of lower energy precipitation, whereas other filaments are the results of a higher flux compared to the surroundings. It was also found that high-energy precipitation corresponds to discrete and dynamic features, including curls, and low-energy precipitation corresponds to auroral signatures that were dominated by rays (Dahlgren et al. 2008b). Further, Dahlgren et al. (2012) identified that mono-energetic approximately $8 \mathrm{keV}$ electron precipitation caused extremely narrow (approximately $70 \mathrm{~m}$ ) and highly dynamic auroral filaments.
Some other fine-scale rapidly varying auroras were reviewed by Sandahl et al. (2008). However, it has been rare that both dynamic spatial variations, such as curls and folds, and rapid time variation of flickering are discussed together, although both features are complementary to diagnose the plasma environment of the M-I coupled region. Also, to the authors' knowledge, there are no examples showing the coexistence of flickering aurora and pulsating aurora especially with its fast ' $3 \pm$ $1 \mathrm{~Hz}$ ' modulations (Royrvik and Davis 1977) at the same time. Note that flickering and pulsating auroras are the results of two completely separate particle precipitation mechanisms. Flickering aurora is associated with particle acceleration of IAW/EMIC waves, whereas pulsations are associated with pitch-angle scattering of chorus waves. Also, flickering aurora is usually associated with breakup in the evening hours, whereas pulsations are more common in the post-midnight early morning. In this letter, we report two interesting examples of finescale compound auroral structures and interpret the simultaneous observations of the auroral features with respect to the known morphological categories to understand the source mechanisms acting concurrently in the magnetosphere-ionosphere coupled system.

\section{Instrumentation}

In February 2014, a new high-speed camera system (NIPR-CMOS) was installed at Poker Flat Research Range (PFRR), Fairbanks, Alaska, and was operated until April 2014. The magnetic latitude is $65.7^{\circ}$ at PFRR, and magnetic midnight is approximately at 11:30 UT. The Hamamatsu scientific complementary metal-oxide semiconductor (sCMOS) camera (ORCA-Flash 4.0, Hamamatsu Photonics, Hamamatsu, Japan) is equipped with NIKKOR 50 mm F1.2 lens (Nikon, Tokyo, Japan) without an optical filter. While the fastest sampling rate of 100 frames per second (fps) is possible with the original pixel array size of 2,048 by 2,048 , we applied 4 by 4 binning and an exposure time of $0.02 \mathrm{~s}(50 \mathrm{fps})$ to enhance the photon count. The camera system was designed to obtain significant counts for bright aurora of $>10 \mathrm{kR}$ at green line. The field-of-view (FOV) is $15^{\circ}$ by $15^{\circ}$ which corresponds to $26.6 \mathrm{~km}$ by $26.6 \mathrm{~km}$ at $100 \mathrm{~km}$ altitude. The camera was oriented so that the FOV captured the magnetic zenith at the center. The relatively larger FOV as used by Kataoka et al. (2011a, 2011b) is one important factor for us to find simultaneous compound features.

In this letter, we show NIPR-CMOS data alone because these particular events did not show any features clearly faster than $25 \mathrm{~Hz}$, which is the Nyquist frequency of NIPR-CMOS. A full-color DSLR camera (Nikon D4 with NIKKOR fish-eye $8 \mathrm{~mm}$ F2.8 lens, Nikon, Tokyo, Japan) was also installed alongside the CMOS cameras to provide an all-sky image every $10 \mathrm{~s}$. 
Two interesting examples are summarized in real-time playing (Additional files 1 and 2). The quality of the obtained images is high enough to make the differential movies (Additional files 3 and 4), which are created by subtracting the previous image at each frame to emphasize the rapidly varying faint features. The differential movie technique is used to investigate the rapid variations in the auroral morphology, and it is another important factor for investigating auroral features as it draws attention to the flickering aurora events.

\section{Results}

Event 1 (19 February 2014 09:30 UT) contains flickering rays and pulsating modulation at the middle of a surge in the pre-midnight sector, during the expansion phase of an intense substorm with the AE index $>1,200 \mathrm{nT}$ just after the storm peak of the Dst index $=-112 \mathrm{nT}$. Event 2
(21 February 2014 12:01 UT) contains growing eddies at the poleward boundary of multiple arcs with localized flickering in the midnight sector, during the expansion phase of a moderate substorm with the AE index $<500$ $\mathrm{nT}$ in the storm recovery phase.

\section{Event 1: flickering rays with pulsating modulation}

Event 1 captures both flickering aurora and pulsating aurora in the pre-midnight sector at approximately 22 MLT. From Figure 1a,b, it is found that diffuse aurora appeared to the west, and discrete aurora appeared to the northeast at the middle of a surge. North-south aligned narrow black aurora is located between these two very different types of aurora. As seen in Additional file 1, and particularly in Additional file 3, the discrete aurora contains flickering rays, while the diffuse aurora consists of pulsating modulation. Figure 1c,d shows the time evolution along
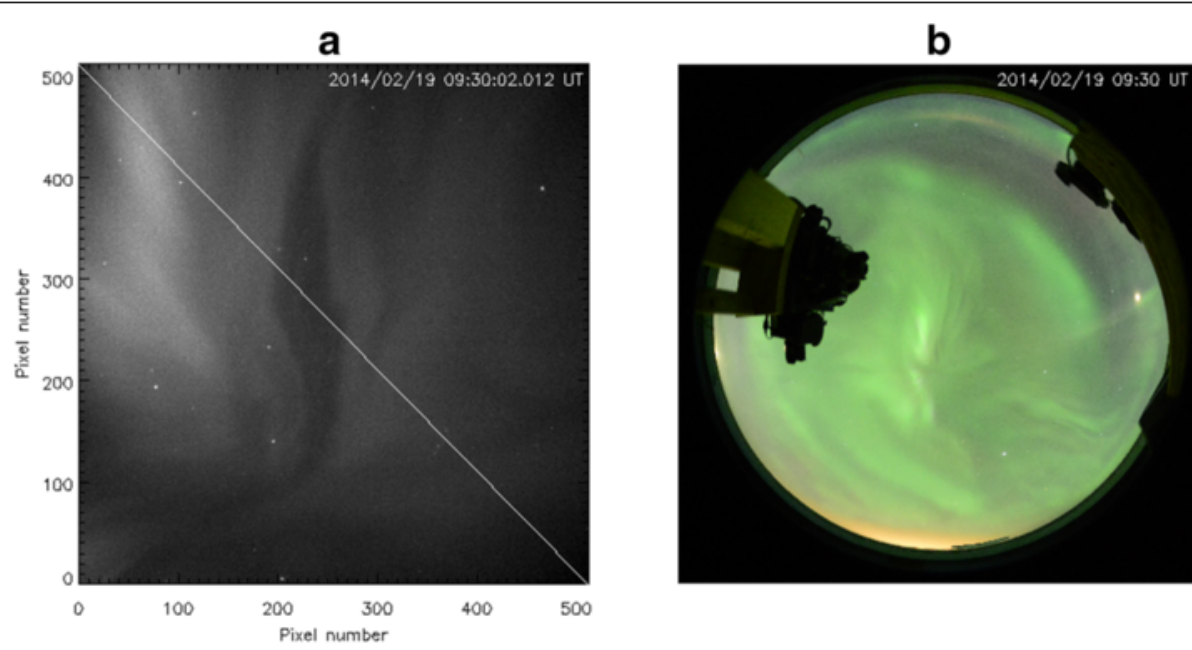

C
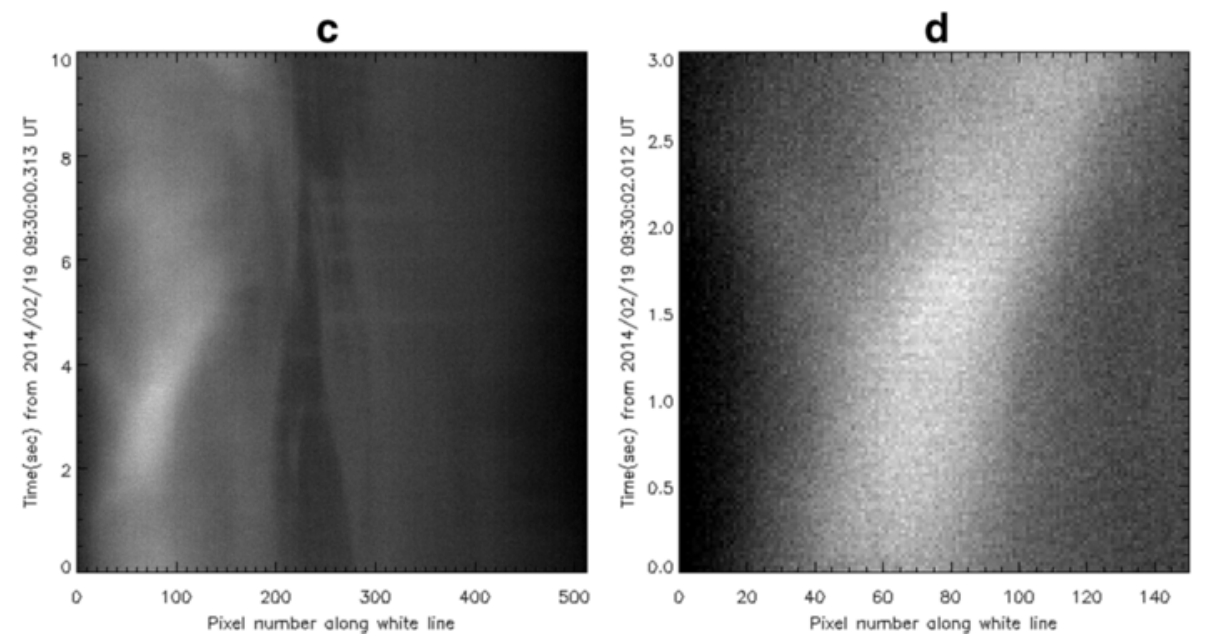

Figure 1 Pulsating aurora appeared to the west, and flickering rays appeared to the northeast. (a) Pulsating aurora appeared to the west, and flickering rays appeared to the northeast in the snapshot at 09:30:02 UT. North is to the top and west is to the right for sub-figures (a) and (b), and the magnetic zenith is at about the center of the image (a). (b) Full-color DSLR all-sky image at 09:30:00 UT shows that the compound structure is located at the middle of a surge. (c) Time evolution along the white line in the panel (a) during a 10-s time period from 09:30:00 UT and $(\mathbf{d})$ the expanded view of the flickering rays are also shown. 
the white line in Figure 1a to partly represent the flickering (Figure 1d) and pulsating modulations (Figure 1c).

Figure 2 shows the distribution map of Fourier spectral amplitude from $1 \mathrm{~Hz}$ to $24 \mathrm{~Hz}$ during the 1-s time interval from 09:30:03 UT to 09:30:04 UT on 19 February 2014, applying the same fast Fourier transform (FFT) analysis as described by Kataoka et al. (2012). The time series averaged over each 4 by 4 pixels is Fourier transformed, and the spectral amplitude distribution of the Fourier transform at each frequency is linearly gray scaled from black to white to see the spatial coverage. The flickering aurora appeared at 12 to $13 \mathrm{~Hz}$ in the rayed structure at the northeast area. Pulsating modulation is also found at 2 to $3 \mathrm{~Hz}$ as seen at the north area.

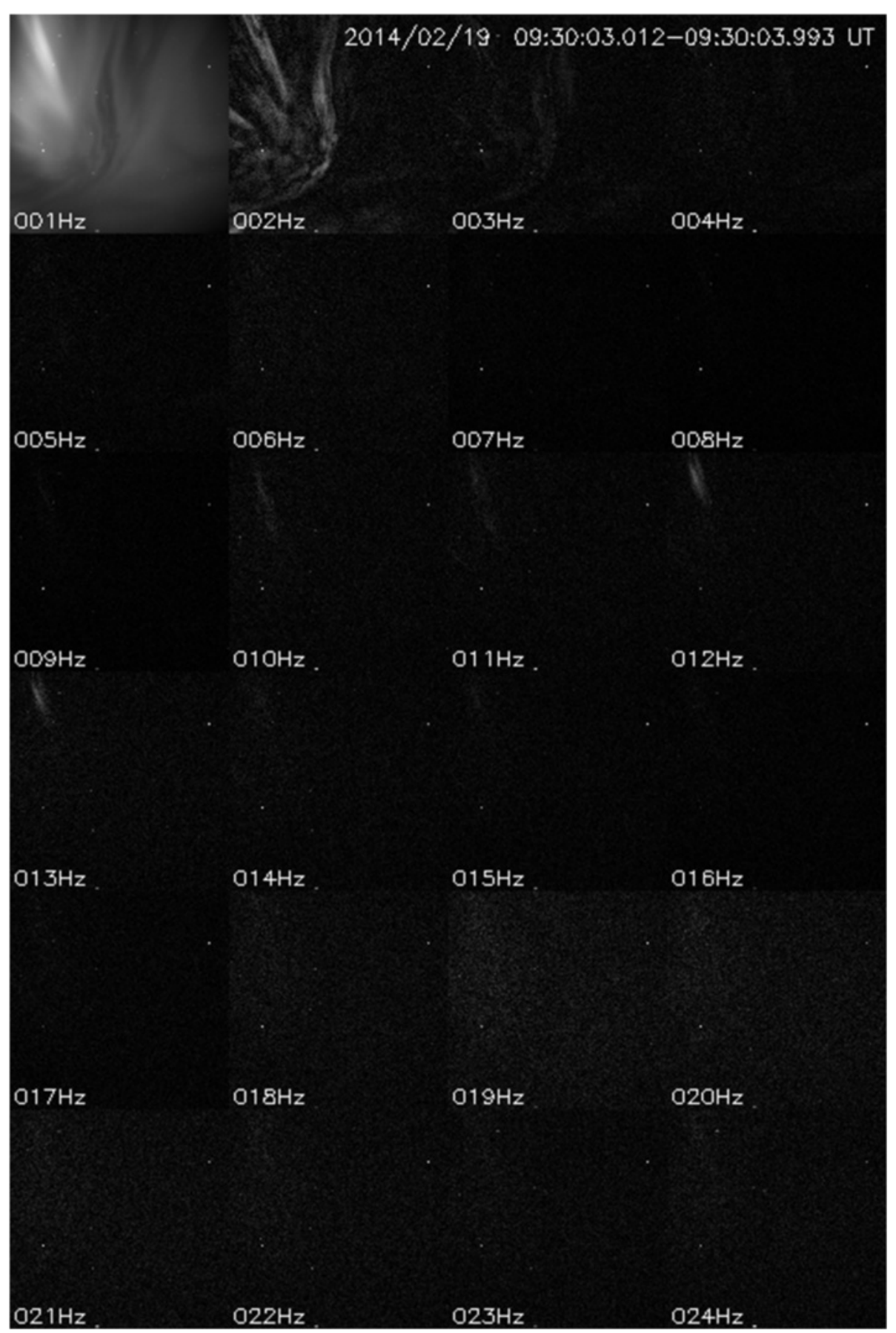

Figure 2 Fourier spectral intensity map at 09:30:03 to 09:30:04 UT on 19 February 2014. Flickering is clear at 12 to $13 \mathrm{~Hz}$, while pulsating modulation is seen at 2 to $3 \mathrm{~Hz}$. 


\section{Event 2: growing eddies with localized flickering}

Figure 3 shows an example of growing eddies near the magnetic midnight sector at approximately 0.5 MLT. The east-west aligned arc is the poleward boundary of a multiple arc system as shown in Figure 3b. Wavy structure with a wavelength of approximately $5 \mathrm{~km}$ at $100 \mathrm{~km}$ altitude appeared at the poleward edge of the arc with 2 to $3 \mathrm{~km}$ width and gradually evolved into eddies of counterclockwise rotation in approximately $10 \mathrm{~s}$. Smallscale vortices flow eastward at 12 to $20 \mathrm{~km} / \mathrm{s}$ as seen in Figure $3 \mathrm{~d}$ and the peaks of the poleward waves drift slowly eastward at an order of $0.1 \mathrm{~km} / \mathrm{s}$ as shown in Figure 3c. Comparing Figure 3c,d during the 4-s time period from 12:01:11 UT to 12:01:15 UT, it is found that the eastward motion of small vortices along the white solid line is approximately $38 \mathrm{~km} / \mathrm{s}$ and which is faster than the approximately $12 \mathrm{~km} / \mathrm{s}$ eastward motion along the dashed line, i.e., eastward motion is faster at the poleward part of the arc. As shown in Additional file 2, the intensity of eddies is quasi-periodically enhanced at every 1 to $2 \mathrm{~s}$ by the passage of a series of bright small vortices flowing eastward in the arc.

By making the differential movie (Additional file 4), it is found that flickering aurora transiently appeared during the growth of eddies at the poleward edge. The position of the relatively strong part of periodic oscillation is highlighted for every frequency in Figure 4, again applying the same FFT analysis as described by Kataoka et al. (2012). It is found that the flickering aurora appeared at below $7 \mathrm{~Hz}$ in a limited area along the arc. However, note that some of the apparent flickering in the FFT analysis could be due to spatial motion in the arc due to the combination of flickering and moving auroral features. This does not affect the conclusion that the flickering has frequencies up to $7 \mathrm{~Hz}$. The strongest real flickering is on the left
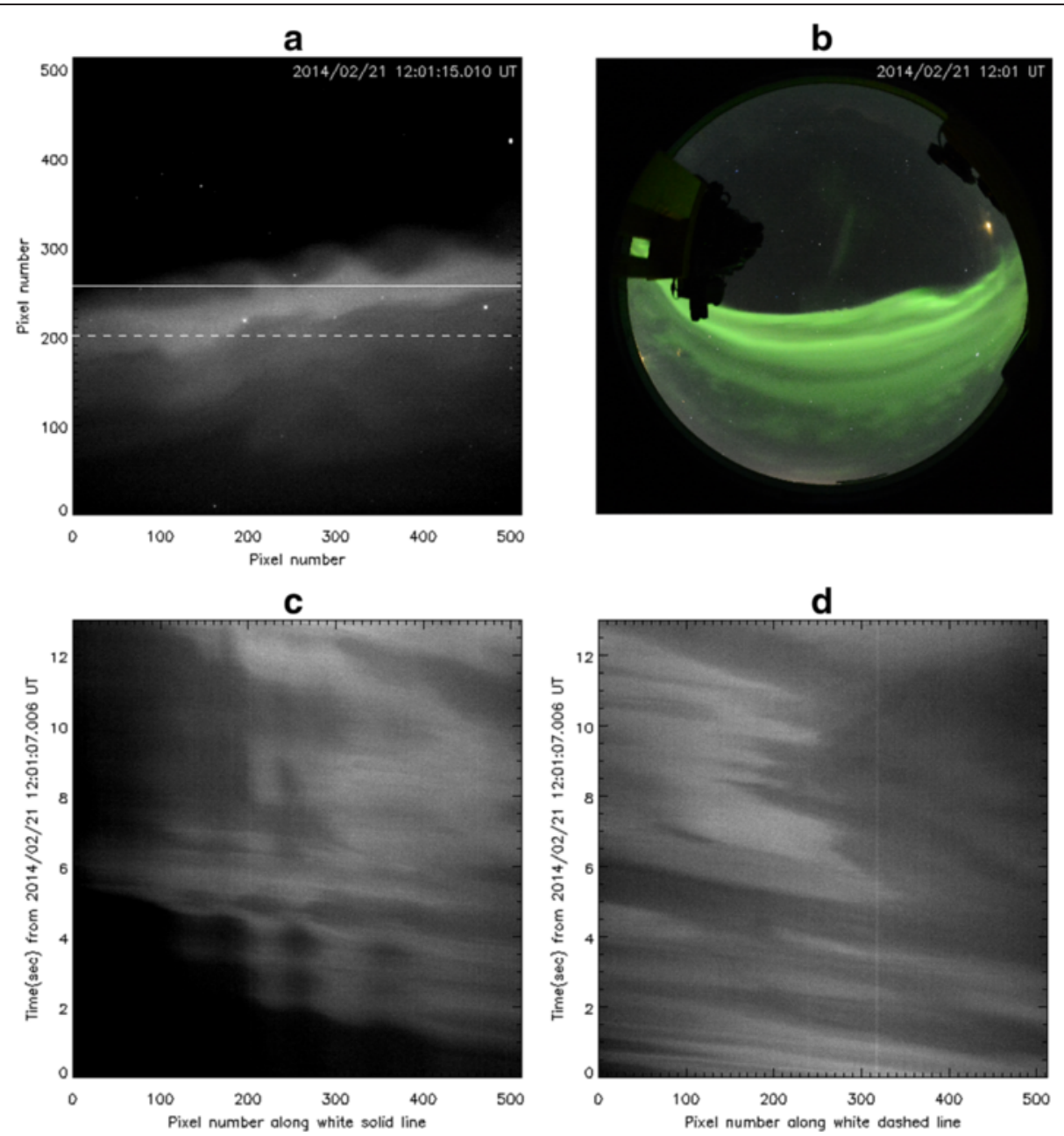

Figure 3 A snapshot of growing eddies is shown at 12:01:15 UT on 21 February 2014 (a). (b) Full-color DSLR all-sky image at 12:01:10 UT shows that the little wavy structure is located at the poleward boundary of an arc system. The formats are the same as Figure 1a,b for sub-figures (a) and (b). Time evolutions of the brightness along the white solid line and dotted line in panel (a) during a 13-s time period from 12:01:07 UT are shown in the panels $(\mathbf{c})$ and $(\mathbf{d})$, respectively. 


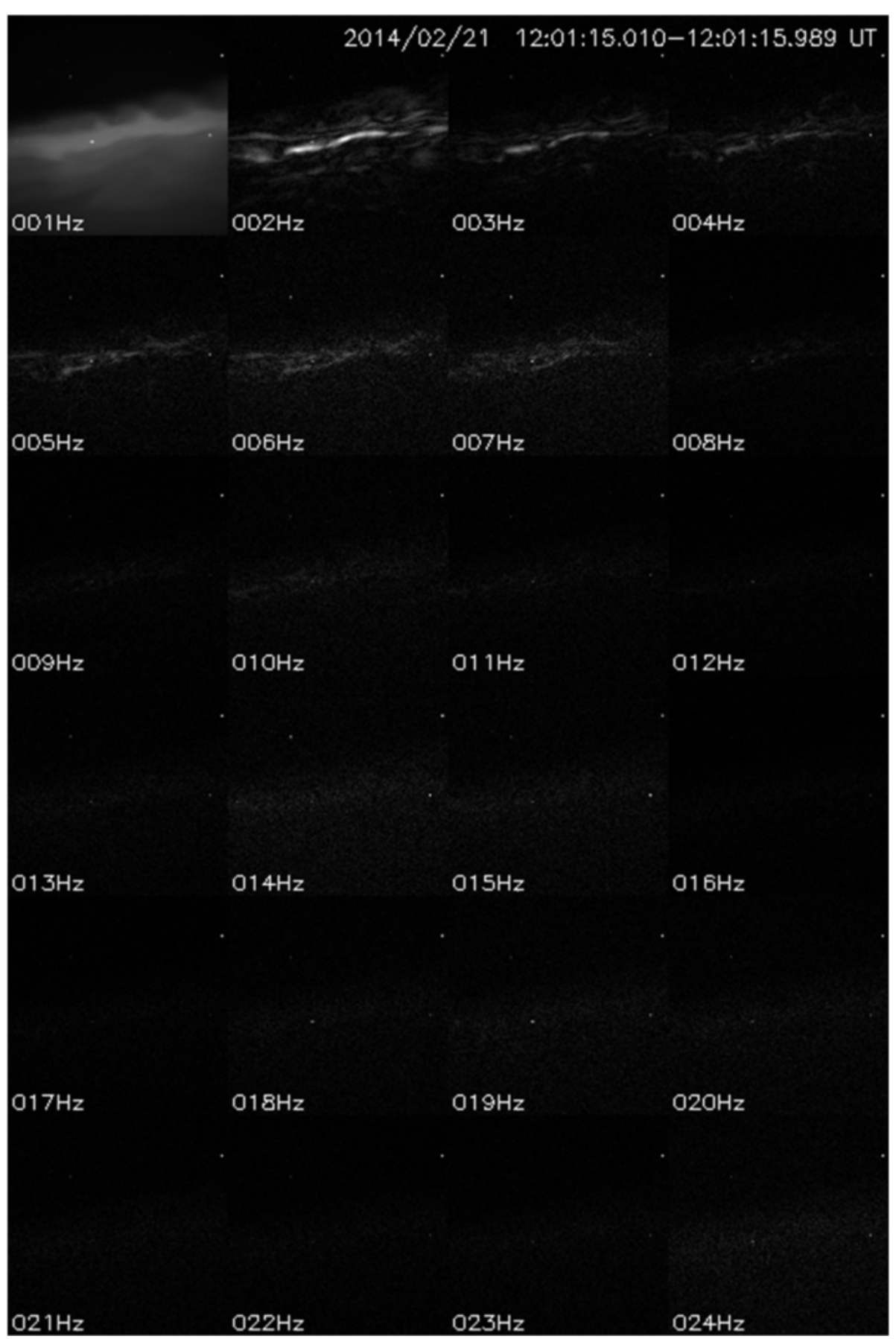

Figure 4 Fourier spectral intensity map at 12:01:15 to 12:01:16 UT on 21 February 2014. The fast variation of less than $7 \mathrm{~Hz}$ can be seen in the localized area within the arc, and there is no feature beyond $8 \mathrm{~Hz}$.

edge of the image at about 12:01:15 UT, and then in the center at about 12:01:17 UT.

\section{Discussion}

In this report, we have briefly reported on observations of compound auroral microstructures using high-resolution optical instrumentation. In event 1 , flickering rays appeared at the middle of surge beside a region of typical pulsating modulation, while in event 2, localized flickering aurora appeared associated with the growing eddies at the poleward edge of an arc system. We discuss the source mechanisms and the possible meanings of these two different compound microstructures. 
For event 1, there is little doubt that the modulation region of the flickering aurora is in the magnetosphereionosphere coupled region as described in the 'Introduction' section, but the closely associated region of pulsating patches was not expected. Many recent studies have confirmed that post-midnight pulsating aurora and their fast modulations during the recovery phase of substorms originate from pitch-angle scattered energetic electrons from the magnetosphere by chorus waves (e.g., Miyoshi et al. 2010; Nishiyama et al. 2012, 2014). Different possible mechanisms of pulsating aurora also exist. For example, Sato et al. (2004) suggested that the modulation of the fieldaligned potential drop may cause pulsating aurora. Because the observed pulsating aurora in this study appeared during the expansion phase of a substorm in the pre-midnight sector, the generation mechanism may be different from the typical post-midnight pulsating aurora during the recovery phase of substorms. It is therefore possible in this case that the source mechanisms of both flickering and pulsating modulation are common or closely involved to achieve the efficient way to dissipate the energy in the M-I coupled region. Further high-speed observations will be important to clarify whether such a coexistence of the flickering aurora and pulsating aurora is a common feature during the expansion phase of substorms.

Event 1 showed the flickering rays, which is consistent with the IAW-accelerated relatively low-energy electrons as suggested by Ivchenko et al. (2005). On the other hand, pulsating aurora, and especially the fast modulation, is the result of more energetic electrons (Sandahl et al. 1980). The simplest interpretation of the coexistence would therefore be that both IAW and also energetic particles of pulsating modulation are enhanced during the expansion phase of the substorm to be launched all together into the ionosphere from the nearby locations in the magnetosphere.

Event 2 is consistent with the local source scenario of IAW (Asamura et al. 2009), associated with the inverted-V type settings as inferred from the evolution of curls and folds (Chaston and Seki 2010). Asamura et al. (2009) showed that vortical discrete auroral forms of approximately $8 \mathrm{~km}$ counter-stream at 14 to $18 \mathrm{~km} / \mathrm{s}$ during the excitation of inertial Alfven waves at approximately $3,000 \mathrm{~km}$ altitude associated with the observed inverted-V electrons. It is therefore possible that the electrostatic shear-induced instability forming the curls and folds (Wagner et al. 1983) is capable of launching IAWs (Asamura et al. 2009) and thereby cause the observed localized flickering aurora. Relatively faint appearance of the localized flickering may be different from typical EMIC-related single-frequency flickering.
It is noteworthy that the growing eddies show counterclockwise rotation (tilted to the east), which is in the wrong direction as expected from the standard KelvinHelmholtz instability if we assume negligibly slow flow at poleward side with the fast eastward bulk flow in the arc. The flow shear within the arc is counterclockwise, i.e., the poleward part moves eastward faster than the equatorial part as described in the 'Event 2: growing eddies with localized flickering' section. The counterclockwise shear setting is consistent with the upward field-aligned current system associated with the locally converging electric field toward the arc. Nonlinear numerical simulations to reproduce the observed features of growing eddies are awaited in order to offer meaningful interpretation.

There are other potentially IAW-related auroras which should be discussed in some detail. Semeter and Blixt (2006) and Semeter et al. (2008) showed that 'arc packets' can be interpreted by the parallel electric field of IAW within the resonance cone. The arc packets occur especially at intense aurora with intense geomagnetic activity. It is noteworthy that Alfven wave propagation on sharp density gradients in a direction transverse to the static magnetic field leads to the formation of a significant parallel electric field (Genot et al. 2004), which gives a spatiotemporal pattern similar to the arc packets. The relationship between arc packets and flickering has not been elucidated yet. It has been measured that field-aligned electron bursts (FABs) are superposed on mono-energetic inverted-V electrons (e.g., McFadden et al. 1987), especially at the edge of the inverted- $\mathrm{V}$, and the whole characteristics is similar to those of flickering aurora. Dahlgren et al. (2013) recently showed that 'flaming' aurora during auroral breakup is consistent with the FABs and is also consistent with $2.4 \mathrm{~Hz}$ flickering. In event 1 , it is still difficult to tell the phase difference of flickering rays with altitude, which might be like flaming or time-of-flight dispersion. It is therefore important to further investigate the occurrence distribution of flaming, flickering, arc packets, and their compound features to distinguish the exact mechanisms and to identify their meaning via highspeed imaging observations. Continuous ground-based high-speed imaging observation of aurora at $>100 \mathrm{fps}$ is possible now (Kataoka et al. 2011a, 2011b; Yaegashi et al. 2011; Nishiyama et al. 2012, 2014). It would be important to pursue the meanings via the occurrence distribution of the fine-scale rapidly varying aurora against meso-scale and global-scale auroral dynamics.

The next important challenge of high-speed optical observations would be the systematic survey of the fastest variation appearing in aurora including the helium and hydrogen cyclotron frequency. Yaegashi et al. (2011) suggested that existence of flickering aurora is related to 
helium ion EMIC waves. Temerin et al. (1986) originally suggested that what appears to be a steady field-aligned flux of auroral electrons can also be produced by hydrogen cyclotron waves since modulation at the hydrogen cyclotron frequency is hardly resolved by current typical sampling rate of $40 \mathrm{~ms}(25 \mathrm{~Hz})$ of particle detectors onboard Reimei satellite, for example. In fact, McFadden et al. (1987) reported the in situ observational results of wave-particle interactions between $\mathrm{H}+\mathrm{EMIC}$ waves (at approximately $120 \mathrm{~Hz}$ ) and down-going field-aligned electron fluxes in inverted $\mathrm{V}$ arcs at approximately 3,700 km altitude. McHarg et al. (1998) reported up to $180 \mathrm{~Hz}$ variation of aurora using ground-based highspeed photometer observations.

\section{Additional files}

Additional file 1: Real-time play of 10-s time variation from 09:30:00 UT to 09:30:10 UT on 19 February 2014. The field-of-view is 15 deg by $15 \mathrm{deg}$, magnetic zenith is about the image center, north is to the top, and west is to the right.

Additional file 2: Real-time play of 13-s time variation from 12:01:07 UT to 12:01:20 UT on 21 February 2014. The format is the same as Additional file 1 .

Additional file 3: Real-time play of differential movie as created from Additional file 1. Real-time play of differential movie as created from Additional file 1 by subtracting the previous image at each frame.

Additional file 4: Real-time play of differential movie as created from Additional file 2. Real-time play of differential movie as created from Additional file 2 by subtracting the previous image at each frame.

\section{Competing interests}

The authors declare that they have no competing interests.

\section{Authors' contributions}

RK designed the camera system, carried out the observation, and drafted the manuscript. YF performed the data analysis. YM helped to design the camera system and to draft the manuscript. $\mathrm{HM}, \mathrm{SI}$, and $\mathrm{DH}$ helped to install the camera system. YE developed the program to control the camera system. $\mathrm{HD}, \mathrm{DW}$, and $\mathrm{Nl}$ advised the interpretation and helped to draft the manuscript. All authors read and approved the final manuscript.

\section{Acknowledgements}

R. K. thanks Kevin Abnett, Naoki Sunagawa, and Ayumi Hashimoto for their help to installing the sCMOS camera systems. RK thanks Tomonao Harada and Nikon professional services for their support by providing Nikon cameras for our observations. This work is supported by Yamada Science Foundation and Grants-in-Aid for Scientific Research (19403010; 25302006) from the Ministry of Education, Culture, Sports, Science and Technology of Japan.

\section{Author details}

'National Institute of Polar Research, 10-3 Midori-cho, Tachikawa, Tokyo 190-8518, Japan. ${ }^{2}$ Department of Polar Science, The Graduate University for Advanced Studies (SOKENDAI), 10-3 Midori-cho, Tachikawa, Tokyo 190-8518, Japan. ${ }^{3}$ Department of Earth and Planetary Science, University of Tokyo, 7-3-1 Hongo, Bunkyo-ku, Tokyo 113-0003, Japan. ${ }^{4}$ Solar-Terrestrial Environment Laboratory, Nagoya University, Furo-cho, Chikusa-ku, Nagoya 464-8601, Japan. ${ }^{5}$ Musashino Art University, 1-736 Ogawa-cho, Kodaira-shi, Tokyo 187-8505, Japan. ${ }^{6} J a p a n$ Science Foundation, 2-1 Kitanomaru Park, Chiyoda-ku, Tokyo 102-0091, Japan. ' Research Institute for Sustainable Humanosphere (RISH), Kyoto University, Gokasho, Uji, Kyoto 611-0011, Japan. ${ }^{8}$ Geophysical Institute, University of Alaska Fairbanks, 903 Koyukuk Drive, Fairbanks, AK 99775-7320, USA. ${ }^{9}$ School of Electrical Engineering, KTH Royal Institute of Technology, S10044 Stockholm, Sweden. ${ }^{10}$ School of Physics and Astronomy, University of
Southampton, Southampton, UK. ${ }^{11}$ Finnish Meteorological Institute, Helsinki, Finland.

Received: 24 August 2014 Accepted: 16 January 2015

Published online: 15 February 2015

\section{References}

Asamura K, Chaston CC, Itoh Y, Fujimoto M, Sakanoi T, Ebihara Y, Yamazaki A, Hirahara M, Seki K, Kasaba Y, Okada M (2009) Sheared flows and small-scale Alfven wave generation in the auroral acceleration region. Geophys Res Lett 36:L05105, doi:10.1029/2008GL036803

Chaston CC, Seki K (2010) Small-scale auroral current sheet structuring. J Geophys Res 115:A11221, doi:10.1029/2010JA015536

Chen L-J, Kletzing CA, Hu S, Bounds SR (2005) Auroral electron dispersion below inverted-V energies: resonant deceleration and acceleration by Alfven waves. J Geophys Res 110:A10S13, doi:10.1029/2005JA011168

Dahlgren H, Ivchenko N, Lanchester BS, Sullivan J, Marklund G, Whiter D (2008a) Morphology and dynamics of aurora at fine scale: first results from the ASK instrument. Ann Geophys 26:1041-1048, doi:10.5194/angeo-26-1041-2008

Dahlgren H, Ivchenko N, Lanchester BS, Sullivan BSJ, Whiter D, Marklund G, Stromme A (2008b) Using spectral characteristics to interpret auroral imaging in the $731.9 \mathrm{~nm}$ O+ line. Ann Geophys 26:1905-1917, doi:10.5194/angeo-26-1905-2008

Dahlgren H, Aikio A, Kaila K, Ivchenko N, Lanchester BS, Whiter DK, Marklund GT (2010) Simultaneous observations of small multi-scale structures in an auroral arc. J Atmos Sol Terr Phys 72:633, doi:10.1016/j.jastp.2010.01.014

Dahlgren H, Ivchenko N, Lanchester BS (2012) Monoenergetic high-energy electron precipitation in thin auroral filaments. Geophys Res Lett 39:L20101, doi:10.1029/2012GL053466

Dahlgren H, Semeter JL, Marshall RA, Zettergren M (2013) The optical manifestation of dispersive field-aligned bursts in auroral breakup arcs. J Geophys Res Space Physics 118:4572-4582, doi:10.1002/jgra.50415

Genot V, Louarn P, Mottez F (2004) Alfven wave interaction with inhomogeneous plasmas: acceleration and energy cascade towards small-scales. Ann Geophys 22:2081-2096

Goertz CK, Boswell RW (1979) Magnetosphere-ionosphere coupling. J Geophys Res 84(A12):7239-7246, doi:10.1029/JA084iA12p07239

Gustavsson B, Lunde J, Blixt EM (2008) Optical observations of flickering aurora and its spatiotemporal characteristics. J Geophys Res 113:A12317, do: 10.1029/2008JA013515

Hallinan TJ (1976) Auroral Spirals 2. Theory J Geophys Res 81(22):3959-3965

Hallinan TJ, Davis TN (1970) Small-scale auroral arc distortions. Planet Space Sci 18:1735-1744

Hasegawa A (1976) Particle acceleration by MHD surface wave and formation of aurora. J Geophys Res 81 (28):5083-5090, doi:10.1029/JA081i028p05083

Ivchenko N, Blixt EM, Lanchester BS (2005) Multispectral observations of auroral rays and curls. Geophys Res Lett 32:L18106, doi:10.1029/2005GL022650

Kataoka R, Miyoshi Y, Sakanoi T, Yaegashi A, Shiokawa K, Ebihara Y (2011a) Turbulent microstructures and formation of folds in auroral breakup arc. J Geophys Res 116:A00K02, doi:10.1029/2010JA016334

Kataoka R, Miyoshi Y, Sakanoi T, Yaegashi A, Ebihara Y, Shiokawa K (2011b) Ground-based multispectral high-speed imaging of flickering aurora. Geophys Res Lett 38:L14106, doi:10.1029/2011GL048317

Kataoka R, Miyoshi Y, Hampton D, Ishii T, Kozako H (2012) Pulsating aurora beyond the ultra-low-frequency range. J Geophys Res 117:A08336, doi:10.1029/2012JA017987

Kunitake M, Oguti T (1984) Spatial-temporal characteristics of flickering spots in flickering auroras. J Geomagn Geoelectr 36:121

Lanchester BS, Rees MH, Lummerzheim D, Otto A, Frey HU, Kaila KU (1997) Large fluxes of auroral electrons in filaments of $100 \mathrm{~m}$ width. J Geophys Res 102 (A5):9741-9748, doi:10.1029/97JA00231

Lanchester BS, Ashrafi M, Ivchenko N (2009) Simultaneous imaging of aurora on small scale in OI $(777.4 \mathrm{~nm})$ and N21P to estimate energy and flux of precipitation. Ann Geophys 27:2881-2891, doi:10.5194/angeo-27-2881-2009

McFadden JP, Carlson CW, Boehm MH, Hallinan TJ (1987) Field-aligned electron flux oscillations that produce flickering aurora. J Geophys Res 92(A10):11133-11148, doi:10.1029/JA092iA10p11133

McHarg MG, Hampton DL, Stenbaek-Nielsen HC (1998) Fast photometry of flickering in discrete auroral arcs. Geophys Res Lett 25(14):2637-2640

Michell RG, McHarg MG, Samara M, Hampton DL (2012) Spectral analysis of flickering aurora. J Geophys Res 117:A03321, doi:10.1029/2011JA016703 
Miyoshi Y, Katoh Y, Nishiyama T, Sakanoi T, Asamura K, Hirahara M (2010) Time of flight analysis of pulsating aurora electrons, considering wave-particle interactions with propagating whistler mode waves. J Geophys Res 115:A10312, doi:10.1029/2009JA015127

Nishiyama T, Sakanoi T, Miyoshi Y, Kataoka R, Hampton D, Katoh Y, Asamura K, Okano S (2012) Fine scale structures of pulsating auroras in the early recovery phase of substorm using ground-based EMCCD camera. J Geophys Res 117:A10229, doi:10.1029/2012JA017921

Nishiyama T, Sakanoi T, Miyoshi Y, Hampton D, Katoh Y, Kataoka R, Okano S (2014), Multi-scale temporal variations of pulsating auroras: on-off pulsation and a few-Hz modulation, J Geophys Res, 119, doi:10.1002/2014JA019818.

Royrvik O, Davis TN (1977) Pulsating aurora: local and global morphology. J Geophys Res 82(29):4720-4740

Sakanoi K, Fukunishi H, Kasahara Y (2005) A possible generation mechanism of temporal and spatial structures of flickering aurora. J Geophys Res 110:A03206, doi:10.1029/2004JA010549

Sandahl I, Eliasson L, Lundin R (1980) Rocket observations of precipitating electrons over a pulsating aurora. Geophys Res Lett 7:309-312, doi:10.1029/GL007i005p00309

Sandahl I, Sergienko T, Brandstrom U (2008) Fine structure of optical aurora. J Atmos Sol Terr Phys 70:2275-2292, doi:10.1016/j.jastp.2008.08.016

Sato N, Wright DM, Carlson CW, Ebihara Y, Sato M, Saemundsson T, Milan SE, Lester M (2004) Generation region of pulsating aurora obtained simultaneously by the FAST satellite and a Syowa-Iceland conjugate pair of observatories. J Geophys Res 109:A10201, doi:10.1029/2004JA010419

Semeter J, Blixt EM (2006) Evidence for Alfven wave dispersion identified in high-resolution auroral imagery. Geophys Res Lett 33:L13106, doi:10.1029/2006GL026274

Semeter J, Zettergren M, Diaz M, Mende S (2008) Wave dispersion and the discrete aurora: new constraints derived from high-speed imagery. J Geophys Res 113:A12208, doi:10.1029/2008JA013122

Temerin M, McFadden J, Boehm M, Carlson CW, Lotko W (1986) Production of flickering aurora and field-aligned electron flux by electromagnetic ion cyclotron waves. J Geophys Res 91(A5):5769-5792, doi:10.1029/JA091iA05p05769

Temerin M, Carlson C, McFadden JP (1993) The acceleration of electrons by electromagnetic ion cyclotron waves, 'Auroral Plasma Dynamics', Geophys. Monogr. Ser., 80, Lysak RL (ed) AGU, Washington, D. C. pp. 155-161, doi:10.1029/GM080p0155

Wagner JS, Sydora RD, Tajima T, Hallinan T, Lee LC, Akasofu S-I (1983) Small-scale auroral arc deformations. J Geophys Res 88(A10):8013-8019, doi:10.1029/JA088iA10p08013

Whiter DK, Lanchester BS, Gustavsson B, Ivchenko N, Sullivan JM, Dahlgren H (2008) Small-scale structures in flickering aurora. Geophys Res Lett 35:L23103, doi:10.1029/2008GL036134

Whiter DK, Lanchester BS, Gustavsson B, Ivchenko N, Dahlgren H (2010) Using multispectral optical observations to identify the acceleration mechanism responsible for flickering aurora. J Geophys Res 115:A12315, doi:10.1029/2010JA015805

Yaegashi A, Sakanoi T, Kataoka R, Asamura K, Miyoshi Y, Sato M, Okano S (2011) Spatial-temporal characteristics of flickering aurora as seen by high-speed EMCCD imaging observations. J Geophys Res 116:A00K04, doi:10.1029/2010JA016333

\section{Submit your manuscript to a SpringerOpen ${ }^{\circ}$ journal and benefit from:}

- Convenient online submission

- Rigorous peer review

- Immediate publication on acceptance

- Open access: articles freely available online

- High visibility within the field

- Retaining the copyright to your article

Submit your next manuscript at $>$ springeropen.com 